\title{
Effect of Using Aqueous Extract of Salvia officinalis L. Leaves on Some Antioxidants Status in Irradiated Rats
}

\author{
S. M. Abd El Fattah, N. M. El-Fatih* and Th. M. Fahim
}

Radiation Biology Dept., *Drug Research Dept, National Centre for Radiation Research and Technology, P. O. Box; 29

Nasr City, Egypt.

\begin{abstract}
AGE (Salvia officinalis L) is an aromatic and medicinal $\checkmark$ plant of Mediterranean origin with antioxidant properties. This study was dedicated to determine the modulatory protective effect of sage water extract against oxidative stress due to radiation exposure injury in male albino rats.

Irradiation was performed as fractionated dose of 6 Grays (Gy) $\gamma$-irradiation delivered as 1.5 Gy two times a week for 2 weeks. Sage leaves water extract was given orally to rats at a dose level of $1 \mathrm{mg} / \mathrm{kg}$ body wt for 14 successive days during and in between exposure to $\gamma$-rays and continued for 7 successive days post irradiation of the rats.

Rats were sacrificed at 7 and 10 days after the last dose of radiation. In irradiated rats group, the results revealed a significant increase of thiobarbituric acid reactive substances (TBARS) while, there was a significant decrease in the activity of reduced glutathione (GSH), superoxide dismutase (SOD), catalase (CAT) activities. In treated-irradiated rats group, water extractable sage leaves application induced a significant improvement in all these tested parameters

It was concluded that the traditional use of sage as an antioxidant is safe and may provide some beneficial effects; and could exhibit modulatory effects on $\gamma$-rays-induced oxidative damage in rats.

Key words: $\gamma$-rays, Salvia officinalis L, antioxidant, rats.
\end{abstract}

The involvement of free radicals reactions in the pathogenesis of liver injury has been investigated for many years. Reactive free radicals can exert cellular damage through a variety of mechanisms, e.g. lipid peroxidation, depletion of glutathione and protein thiols, derangement of intracellular free calcium homeostasis and DNA fragmentation, with different relevance in the various conditions (Oboh and Henle, 2009). 
Ionizing radiation particles interact with biological systems to induce excessive reactive oxygen species (ROS), which attack various cellular components including DNA, proteins and membrane lipids, thereby leading to significant cellular damage (Kohen and Nyska, 2002). ROS initiates the chain reactions that peroxidize polyunsaturated fatty acids in membrane phospholipids (Friedman, 2000). Oxidative stress might represent a direct or indirect relevant pro-fibrogenic stimulus for hepatic cells (Huang et al., 2005).

Detoxification of superoxide anion $\left(\mathrm{O}_{2}^{-}\right)$and hydrogen peroxide $\left(\mathrm{H}_{2} \mathrm{O}_{2}\right)$, catalyzed by intracellular superoxide dismutase (SOD), catalase (CAT) and glutathione peroxidase (GSH-Px) enzyme activities represents a major line of defence (Gutteridge, 1995). However, the continuously increased ROS productions has been negatively impact the internal antioxidant defence mechanisms (Song et al., 2006). Thus, scavenging free radicals and inhibiting lipid peroxidation are likely key target activities for developing successful radio-protection strategies.

Experimental evidence suggests that most herbs and spices, especially those of the Lamiaceae family, possess a wide range of biological and pharmacological activities that may protect tissues against $\mathrm{O}_{2}$-induced damage and therefore lower the risk of human chronic diseases (Bozin et al, 2006).

Salvia, the largest genus of the Lamiaceae family, includes about 900 species, spread throughout the world, some of which are economically important since they have use as spices and flavouring agents in perfumery and cosmetics.

Many species of Salvia, including sage, have been used as traditional herbal medicine against a variety of diseases. The plant is reported to have a wide range of biological activities, such as anti-oxidative properties (Hohmann et al., 1999), anti-bacterial (Bozin, et al., 2007), hypoglycemic (AlarconAguilar et al., 2002), anti-inflammatory (Baricevic et al., 2001), fungistatic, virustatic, astringent, eupeptic and anti-hydrotic effects (Farag et al., 1986). Sage acts as antidiabetic agent in the study performed by (Eidi et al., 2005). Also Sookto et al., (2013) showed that the oil extract of sage exhibited good antifungal activity.

Egypt. J. Rad. Sci. Applic., Vol. 26, No. 1-2 (2013) 
The aim of the present study was to establish the putative protective and restorative role of sage against radiation-induced oxidative-stress in hepatic tissues and blood system.

\section{Materials and Methods}

\section{Experimental animals}

Sprague Dawley male albino rats $(120 \pm 10 \mathrm{~g})$ were obtained from The Holding Company for Biological Products and Vaccines (VACSERA), Cairo, Egypt. The Animals were kept in isolated cages, under standard laboratory conditions including all hygienic measures with constant illumination and ventilation, temperature and humidity. Animals were maintained on a starter poultry pellets and water ad libitum. All animals were housed within a certified animal care facility. Animal husbandry and experimentation were compatible with the Public Health Guide for the care and Use of Laboratory animals (National Research Council, 1996) and in accordance with protocols approved by the local experimental animal ethics committee.

\section{Preparation of plant extract}

Plants were purchased from local market. Considering that sage is traditionally used as a tea, an infusion of sage was routinely prepared by pouring $150 \mathrm{ml}$ of boiling water onto $2 \mathrm{~g}$ of the dried plant material and allowing to steep for $5 \mathrm{~min}$. This produced an infusion of $3.5 \pm 0.1 \mathrm{mg}$ of extract dry weight per $\mathrm{ml}$ of infusion $(0.35 \% \mathrm{w} / \mathrm{v})$ and a yield of $26.3 \%(\mathrm{w} / \mathrm{v})$ in terms of initial crude plant material dry wt (Lima et al., 2005).

\section{Radiation process}

Irradiation processing was performed using a Canadian Gamma Cell-40, $\left({ }^{137} \mathrm{Cs}\right)$ at NCRRT, Cairo, Egypt. Animals were submitted to fractionated whole body $\gamma$-radiation; 2 Gy instalments every week at a dose rate of $0.5 \mathrm{~Gy} / \mathrm{min}$ up to 6 Gy (total dose).

\section{Experimental design}

Animals were divided into 4 groups (each of 6 rats): control group, sage treated group ( $1 \mathrm{ml} / \mathrm{Kg}$ body wt) for 35 days, irradiated group was exposed to fractionated dose of $\gamma$-irradiation (6 Gy) delivered as 1.5 Gy 2 times per week 
for 2 weeks and sage treated $+\gamma$-irradiated animals; this group received sage for 14 successive days before exposure to fractionated dose of $\gamma$-irradiation and daily within the period of irradiation, and then received sage for seven days post radiation exposure.

\section{Samples collection}

Animals were fasted overnight prior to sacrificing. Sex animals from each group were randomly sacrificed by cervical dislocation 7 and 10 days post irradiation. Blood samples were obtained by heart puncture from the anaesthetized rats.

Plasma samples were prepared by centrifugation at 3000 r.p.m. and liver samples were collected and prepared following normal laboratory procedures, for the measurement of the biochemical parameters.

\section{Biochemical procedures}

Lipid peroxide content was determined by quantifying the TBARS content in blood and tissue homogenates according to the method described by Yoshioka et al. (1979). SOD activity was determined according to the method of Minami and Yoshikawa (1979). CAT activity was determined according to the method described by Johansson and Hakan Borg (1988). Determination of GSH content was performed according to the procedure of Beutler et al. (1963).

\section{Statistical analysis}

Data were reported as means \pm S.E. The results were submitted to one-way ANOVA, and means were compared between groups by Duncan's multiple range tests and least-significant difference (LSD) test. Results were considered statistically significant when $P$-value $<0.05$ (SAS "Statistical Analysis System", 2008).

\section{Results}

The antioxidants status SOD and CAT activities and GSH, TBARS concentrations in liver and blood are presented in Tables (1, 2, $3 \&$ \& 4). The experimental results pointed to a significant increased changes in the activity of SOD and CAT in liver and mildly decreased activity in the blood in rats subjected to $\gamma$-radiation $(P \leq 0.05)$ (Table $1 \& 2)$.

Egypt. J. Rad. Sci. Applic., Vol. 26, No. 1-2 (2013) 
TABLE 1. Effect of treatment of irradiated rats with sage on SOD activity.

\begin{tabular}{|c|c|c|c|c|}
\hline \multirow{2}{*}{$\begin{array}{c}\text { Tissues \& } \\
\text { Times of investigations }\end{array}$} & \multicolumn{4}{|c|}{ Animal groups } \\
\cline { 2 - 5 } Liver (mIU/ mg protein) & Control & Sage & IRR & Sage+ IRR \\
7 days & $36.57 \pm 1.42$ & $38.20 \pm 1.12$ & $50.00 \pm 1.63^{*}$ & $40.30 \pm 1.72^{\#}$ \\
10 days & $37.80 \pm 1.40$ & $37.47 \pm 1.20$ & $43.44 \pm 1.20^{*}$ & $30.85 \pm 1.55^{* \#}$ \\
\hline Blood (U/g Hb) & & & & \\
7days & $437.80 \pm 25.00$ & $415.00 \pm 23.70$ & $308 \pm 14.0^{*}$ & $360 \pm 18.00^{* \#}$ \\
10 days & $450.00 \pm 26.70$ & $440.00 \pm 25.00$ & $299 \pm 12.8^{*}$ & $351 \pm 20.0^{* \#}$ \\
\hline
\end{tabular}

Each value represents the mean of 6 records \pm S.E. IRR= irradiated group.

* Significantly different from control group at $\mathrm{p}<0.05$.

\# Significantly different from a corresponding irradiated group at $\mathrm{p}<0.05$.

However, there was a marked significant reduction in blood and liver GSH level (Table 3 ) in the $\gamma$-irradiated group (6 Gy) as compared to that of control groups.

TABLE 2. Effect of treatment of irradiated rats with sage on CAT activity.

\begin{tabular}{|c|c|c|c|c|}
\hline \multirow{2}{*}{$\begin{array}{c}\text { Tissues \& } \\
\text { Times of investigations }\end{array}$} & \multicolumn{4}{|c|}{ Animal groups } \\
\cline { 2 - 5 } Liver (U/ g protein) & & Sage & IRR & Sage + IRR \\
7 days & $2.99 \pm 0.18$ & $2.85 \pm 0.14$ & $4.00 \pm 0.24^{*}$ & $3.23 \pm 0.12^{\#}$ \\
10 days & $3.05 \pm 0.16$ & $2.95 \pm 0.15$ & $2.00 \pm 0.13^{*}$ & $2.46 \pm 0.14^{* \#}$ \\
\hline Blood (U/g Hb) & & & & \\
7days & $12.10 \pm 0.56$ & $11.90 \pm 0.75$ & $7.47 \pm 0.22^{*}$ & $9.80 \pm 0.45^{* \#}$ \\
10 days & $12.83 \pm 0.60$ & $12.22 \pm 0.67$ & $6.53 \pm 0.27^{*}$ & $8.61 \pm 0.44^{* \#}$ \\
\hline
\end{tabular}

Legends as in Table 1 .

The results obtained showed remarkable improvement in SOD, CAT and GSH levels in rat's administered prolonged sage before and during irradiation exposure as compared with a corresponding data of those irradiated only.

TABLE 3. Effect of treatment of irradiated rats with sage on GSH activity.

\begin{tabular}{|c|c|c|c|c|}
\hline \multirow{2}{*}{$\begin{array}{c}\text { Tissues \& } \\
\text { Times of investigations }\end{array}$} & \multicolumn{4}{|c|}{ Animal groups } \\
\cline { 2 - 5 } Liver (mg/g fresh tissue) & Control & Sage & IRR & Sage + IRR \\
7 days & $30.33 \pm 2.14$ & $32.33 \pm 1.67$ & $22.90 \pm 1.23^{*}$ & $23.68 \pm 0.96^{*}$ \\
10 days & $31.33 \pm 2.33$ & $34.00 \pm 1.63$ & $17.83 \pm 1.05^{*}$ & $23.27 \pm 1.13^{* \#}$ \\
\hline Blood (mg/ 100 ml RBCs) & & & & \\
7days & $53.13 \pm 1.82$ & $54.17 \pm 1.33$ & $37.92 \pm 0.69^{*}$ & $44.33 \pm 2.16^{* \#}$ \\
10 days & $49.80 \pm 1.44$ & $51.50 \pm 1.93$ & $34.42 \pm 1.44^{*}$ & $40.67 \pm 2.51^{* \#}$ \\
\hline
\end{tabular}

Legends as in Table 1. 
Furthermore, the concentration of TBARS showed a significant increase due to $\gamma$ - irradiation as compared to that of control rats. This observation was found in examined liver tissues in addition to blood; $P \leq 0.05$, Table 4 . at the ${ }^{7}$ th and 10th days of experimental intervals.

TBARS concentration in liver and plasma were significantly decreased post sage treatment as compared to $\gamma$-irradiated rats (Table 4).

TABLE 4. Effect of treatment of irradiated rats with sage on TBARS content.

\begin{tabular}{|c|c|c|c|c|}
\hline \multirow{2}{*}{$\begin{array}{c}\text { Tissues \& } \\
\text { Times of investigations }\end{array}$} & \multicolumn{4}{|c|}{ Animal groups } \\
\cline { 2 - 5 } & Control & Sage & IRR & Sage + IRR \\
\hline Liver (n mol/g fresh tissue) & & & & \\
7 days & $238 \pm 11.00$ & $237 \pm 13.00$ & $388 \pm 18.00^{*}$ & $300 \pm 17.00^{* \#}$ \\
$\mathbf{1 0}$ days & $245 \pm 10.00$ & $240 \pm 14.00$ & $400 \pm 15.00^{*}$ & $310 \pm 15.00^{* \#}$ \\
\hline Plasma (n mol/ ml) & & & & \\
7days & $11.20 \pm 0.80$ & $10.90 \pm 0.72$ & $21.0 \pm 1.7^{*}$ & $14.10 \pm 1.10^{* \#}$ \\
$\mathbf{1 0}$ days & $10.97 \pm 0.77$ & $10.78 \pm 0.70$ & $22.7 \pm 2.0^{*}$ & $15.0 \pm 1.47^{* \#}$ \\
\hline
\end{tabular}

Legends as in Table 1.

\section{Discussion}

Several evidences had indicated that accumulation of ROS led to the alteration in a wide range of gene expression, such as antioxidant-enzymes, stress response genes and cytokines (Zhang et al., 2002). During oxidativestress, the endogenous antioxidant defences are likely to be weakened because of overproduction of oxygen radicals, consumption of antioxidants and failure to adequately replenish these antioxidant enzymes in tissues (Droge, 2002).

The increased oxidative stress induced by radiation exposure was associated with a significant alteration in antioxidant status pronounced by the significant difference in SOD and CAT activity in the liver and blood and a marked depletion in GSH concentration as compared to values of control. SOD is a key antioxidant enzyme in the metabolism of oxygen free radicals. They catalyze the dismutation of superoxide anion radical, a common product of molecular oxygen reduction, to oxygen and hydrogen peroxide (Balin and Allain, 1986). Since SOD is present in all aerobic organisms and most (if not all) subcellular compartments that generate activated oxygen, it has been assumed that SOD has a central role in the defence against oxidative stress (Bowler et al., 1992). Bowler et al. (1992) have suggested that unique lipid 
peroxidation products could diffuse from the site of oxidative damage to the nucleolus where they would enhance transcription of specific SOD genes. Numerous studies have shown the importance of SOD in protecting cells against oxidative stress (Huang, 1997). Thus, the decreased activity of SOD observed in the present study could be due to a feedback inhibition or oxidative inactivation of enzyme protein due to excess ROS generation.

CAT directly neutralizes the $\mathrm{H}_{2} \mathrm{O}_{2}$ produced from the superoxide dismutation reaction into water and molecular oxygen. Stress conditions which reduce the rate of protein turnover, such as salinity, heat shock or cold, radiation exposures cause the depletion of CAT activity (Hertwig et al., 1992). Depletion of the activity of blood and liver tissues of irradiated rats SOD, CAT may be due to the increased utilization of these antioxidants to counter lipid peroxidation (Kalpana and Menon, 2004).

GSH is the most abundant non-protein sulfhydryl-containing compound and constitutes the largest component of the endogenous thiol buffer (Holmgren et al., 2005). Assessment of GSH in biological samples is essential for evaluation of the redox homeostasis and detoxification status of cells in relation to its protective role against oxidative and free radical-mediated cell injury (Rossi et al., 2005). The present study, recorded a significant depletion of blood and liver tissues GSH concentration in animals exposed to $\gamma$-radiation, compared to that of control groups.

GSH has diverse cellular functions in addition to its antioxidant properties including enzymatic conjugation through the glutathione S-transferase family of proteins and non-enzymatic conjugation to cytotoxic compounds (Davis et al., 2001). Depletion in GSH level after radiation exposure might be resulted from diffusion through impaired cellular membranes and/ or inhibition of GSH synthetase and glutathione reductase enzymes (Kooij et al., 1994). In the present study, the depression of this enzyme activity reflects perturbations in normal oxidative mechanisms during irradiation exposure.

Fractionated dose of $\gamma$-irradiation in the present study induced a significant increase in the activity of serum lipid peroxidation associated with decrease in antioxidant enzymes. Lipid peroxidation was found to be a feature of many types of cell injury, in which free radical intermediates were produced in excess 
to endogenous enzymatic and non-enzymatic defence mechanisms (Slater, 1984). Lipid peroxidation can lead to changes in cell membrane fluidity and permeability; consequently, cellular functions depending on membrane integrity were prone to oxidative alterations and cytotoxicity (Esterbauer et al., 1991 and Geetha et al., 2004).

The recorded increment in TBARS contents could be explained on the basis that, ionizing radiation induced lipid peroxidation through the generation of ROS which attack the polyunsaturated fatty acids constituents of the cell membrane and other cell biomolecules, initiates a self-perpetuating chain reaction that yields a wide range of cytotoxic breakdown by-products such as TBARS (Gutteridge, 1995). Thus TBARS can serves as a reliable marker of oxidative stress-mediated lipid peroxidation (Oktem et al., 2004).

Lipid peroxidation plays a role in the cytotoxic effects of oxidant-based chemotherapeutic and phototherapeutic drugs (Girotti and Kriska, 2004). Thus, scavenging free radicals and inhibiting lipid peroxidation are likely key target activities of developing successful radioprotection strategies (Fridovich, 1986).

The study of Lima et al. (2007) clearly showed the antioxidant effects at cellular level of sage, namely preventing cell death, lipid peroxidation and GSH depletion in human hepatoma cell line (HepG2). The protection of cell viability conferred by sage extracts seemed to be due mainly to their ability to prevent GSH depletion (by about 60\%). This study also showed a good correlation of the above cellular effects of sage with the effects of their main phenolic compounds, rosmarinic acid and luteolin-7-glucoside. Nevertheless, unknown compounds other than phenolics also seem to contribute to the antioxidant effects of sage on basal GSH levels. The same study showed for the first time the ability of sage (mainly the methanolic extract) to increase basal GSH levels, probably by the induction of glutathione synthesis.

$\mathrm{Lu}$ and Foo (2000) observed that sage extracts contain flavonoids and other phenolics which may contribute to the total antioxidant activity.

Main activities of rosmarinic acid include antioxidant, antiinflammatory, anti-mutagenic, antibacterial, and antiviral properties (Armatu et al., 2010 and Petersen and Simmonds, 2003).

Egypt. J. Rad. Sci. Applic., Vol. 26, No. 1-2 (2013) 
Sá et al. (2009) concluded that a four week treatment with sage tea was effective in the improvement of lipid profile, antioxidant defences and lymphocyte Hsp70 protein expression of human volunteers, which in the long term may be responsible for the general health improving properties attributed to sage.

Walch et al. (2011) suggested that on average between 3 and 6 cups of sage tea could be daily consumed without reaching toxicological thresholds. It could be postulated that the hepatoprotective effect of sage may be, at least in part, due to their inhibitory ability on membrane lipid peroxidation and free radical formation or due to their free radical scavenging ability. Ultimately, the results suggest that sage could be used as a potent exogenous cytoprotective agent against cell oxidative damage. Meantime, it could be used as a template for designing novel drugs to combat diseases induced by oxidative stress components.

It could be postulated that the hepatoprotective effect of sage may be, at least in part, due to their inhibitory ability on membrane lipid peroxidation and free radical formation or due to their free radical scavenging ability. Ultimately, the results suggest that sage could be used as a potent exogenous cytoprotective agent against cell oxidative damage. Meantime, it could be used as a template for designing novel drugs to combat diseases induced by oxidative stress components.

\section{References}

Alarcon-Aguilar, F. J., Roman-Ramos, R., Flores-Saenz, J. L. and Aguirre-Garcia, F. (2002) Investigation on the hypoglycaemic effects of extracts of four Mexican medicinal plants in normal and alloxan-diabetic mice. Phytother. Res., 16, 383.

Armatu, A., Colceru-Mihu, S., Bubueanu, C., draghici, E and Pirvu, L. (2010) Evaluation of antioxidant and free scavenging potential of some Lamiaceae species growing in Romania. Roman. Biotechnol. Lett., 15, 5274.

Balin, A. K. and Allen, R. G. (1986) Mechanisms of biological aging. Dermat. Clin., 4, 347 .

Baricevic, D., Sosa, S., Della, L. R., Tubaro, A., Simonovska, B., Krasna, A. and Zupancic, A. (2001) Topical anti-inflammatory activity of Salvia officinalis L. leaves: the relevance of ursolic acid. J. Ethnopharm., 75, 125. 
Beutler, E., Duron, O. and Kelly, B. M. (1963) Improved method for determination of blood glutathione. J. Lab. Clin. Med., 61, 882.

Bowler, C., Van Montagu, M. and Inzé, D. (1992) Superoxide dismutase and stress tolerance. Annu. Rev. Plant Physiol. Mol. Biol., 43, 83.

Bozin, B., Mimica-Dukic, N., Simin, N. and Anackov, G. (2006) Characterization of the volatile composition of essential oils of some lamiaceae spices and the antimicrobial and antioxidant activities of the entire oils. J. Agric. Food Chem., 54, 1822.

Bozin, B., Mimica-Dukic, N., Samojlik, I. and Jovin, E. (2007) Antimicrobial and antioxidant properties of rosemary and sage (Rosmarinus officinalis L. and Salvia officinalis L., Lamiaceae) essential oils. J. Agric. Food Chem., 55, 7879.

Davis, W. Jr., Ronai, Z. and Tew, K. D. (2001) Cellular thiols and reactive oxygen species in drug-induced apoptosis. J. Pharmacol. Exp. Ther., 296, 1.

Droge., W. (2002) Free radicals in the physiological control of cell function. Physiol. Rev., 82, 47.

Eidi, M., Eidi, A. and Zamanizadeh, H. (2005) Effect of Salvia officinalis L. leaves on serum glucose and insulin in healthy and streptozotocin-induced diabetic rats. J. Ethnopharmacol., 100, 310.

Esterbauer, H., Schaur, R. J. and Zoilner, J. (1991) Chemistry and biochemistry of 4-hydroxynonenal malondialdehyde and related aIdehydes. Free Radic. Biol. Med., 11, 82 .

Farag., R. S., Salem, H., Badei, A. Z. and Hassanein, D. E. (1986) Biochemical studies on the essential oil of some medicinal plants. Fette Seifen Anstrichmittel., 88, 69.

Fridovich, I. (1986) Biological effects of the superoxide radical. Arch. Biochem. Biophys., 247, 1.

Friedman, S. L. (2000) Molecular regulation of hepatic fibrosis, an integrated cellular response to tissue injury. J. Biol. Chem., 275, 2247.

Geetha, S., Kedlaya, R. and Vasudevan, D. M. (2004) Inhibition of lipid peroxidation by botanical extracts of Ocimum sanctum: In vivo and in vitro studies. Life Sci., 76, 21.

Girotti, A. W. and Kriska, T. (2004) Role of lipid hydroperoxides in photo-oxidative stress signaling. Antioxid. Redox Signal., 6, 301.

Gutteridge, J. M. (1995) Lipid peroxidation and antioxidants as biomarkers of tissue damage. Clin. Chem., 41, 1819.

Hertwig, B., Steb, P. and Feierabend, J. (1992) Light dependence of catalase synthesis and degradation in leaves and the influence of interfering stress conditions. Plant Physiol., 100, 1547.

Egypt. J. Rad. Sci. Applic., Vol. 26, No. 1-2 (2013) 
Hohmann, J., Zupko, I., Redei, D., Csanyi, M., Falkay, G., Mathe, I. and Janicsak, G. (1999) Protective effects of the aerial parts of Salvia officinalis, Melissa officinalis and Lavandula angustifolia and their constituents against enzymedependent and enzyme-independent lipid peroxidation. Planta Med., 65, 576.

Holmgren, A., Johansson, C., Berndt, C., Lonn, M. E., Hudemann, C. and Lillig, C. H. (2005) Thiol redox control via thioredoxin and glutaredoxin systems. Biochem. Soc. Trans., 33, 1375.

Huang, T. T., Yasunami, M., Carlson, E. J., Gillespie, A. M., Reaume, A. G., Hoffman, E. K. and Chan, P. H. (1997) Superoxide mediated cytotoxicity in superoxide dismutase deficient fetal fibroblasts. Arch. Biochem. Biophys., 344, 424.

Huang., S. Z., Luo, Y. J., Wang, L. and Cai, K. Y. (2005) Effect of ginkgo biloba extract on livers in aged rats. World J. Gastroenterol., 11, 132.

Johansson, L. H. and Hakan Borg, L. A. (1988) A spectrophotometric method for determination of catalase activity in small tissue samples. Anal. Biochem., 174, 331 .

Kalpana, C. and Menon, V. P. (2004) Modulatory effects of curcumin on lipid peroxidation and antioxidant status during nicotine-induced toxicity. Pol. J. Pharmacol., 56, 581.

Kohen, R. and Nyska, A. (2002) Oxidation of biological systems: Oxidative stress phenomena, antioxidants, redox reactions, and methods for their quantification. Toxicol. Path., 30, 620.

Kooij, A., Schiller, H. J., Schijns, M., Van-Noorden, J. F. and Fredricks, W. M. (1994) Conversion of xanthine dehydrogenase into xanthine oxidase in rat liver and plasma at the onset of reperfusion after ischemia. Hepatology, 9, 1488.

Lima, C. F., Andrade, P. B., Seabra, R. M., Fernandes-Ferreira, M. and PereiraWilson, C. (2005) The drinking of a Salvia officinalis infusion improves liver antioxidant status in mice and rats. J. Ethnopharmacol., 28, 383.

Limaa, C. F., Valentao, P. C. R., Andrade, P. B., Seabra, R. M., FernandesFerreira, M. and Pereira-Wilson, C. (2007) Water and methanolic extracts of Salvia officinalis protect HepG2 cells from $t$-BHP induced oxidative damage. Chem. Biol. Interact., 167, 107.

Lu, Y., and Foo, L. Y. (2000) Flavonoid and phenolic glycosides from Salvia officinalis. Phytochemistry, 55, 263.

Minami, M. and Yoshikawa, H. (1979) A simplified assay method of superoxide dismutase activity for clinical use. Clinica Chimica Acta, 92, 337.

Oboh, G. and Henle, T. (2009) Antioxidant and inhibitory effects of aqueous extracts of salvia officinalis leaves on pro-oxidant-induced lipid peroxidation in brain and liver in vitro. J. Med. Food, 12, 77 .

Egypt. J. Rad. Sci. Applic., Vol. 26, No. 1-2 (2013) 
Oktem, F., Arslan, M. K. and Dundar, B. (2004) Renal effects and erythrocyte oxidative stress in long term leadexposed adolescent workers in auto repair workshops. Arch. Toxicol., 78, 681.

Petersen, M. and Simmonds, M. S. (2003) Rosmarinic acid. Phytochemistry, 62, 121.

Rossi, R., Dalle-Donne, I., Milzani, A. and Giustarini, D. (2005) Oxidized forms of glutathione in peripheral blood as biomarkers of oxidative stress. Clin. Chem., 52, 1406.

Sá, C. M., Ramos, A. A., Azevedo, M. F., Lima, C. F., Fernandes-Ferreira M. and Pereira-Wilson, C. (2009) Sage tea drinking improves lipid profile and antioxidant defences in humans. Int. J. Mol. Sci., 10, 3937.

SAS Institute (2008) SAS/STAT User's Guide Introduction to Statistical Modelling with SAS/STAT Software, SAS Institute Inc., Cary, NC, USA.

Slater, T. F. (1984) Free-radical mechanisms in tissue injury. Biochem. J. 222, 1.

Song, L.H., Yan, H.L. and Cai, D.L. (2006) Protective effects of soybean isoflavone against gamma-irradiation induced damages in mice. J. Radiat. Res., 47, 157.

Sookto, T., Srithavaj, T., Thaweboon, S., Thaweboon, B., Shrestha, B. and Nakazawa, F. (2013) In vitro effects of Salvia officinalis L. essential oil on Candida albicans. Asian Pac. J. Trop. Biomed., 3, 376.

Walch, S. G., Kuballa, T., Stühlinger, W. and Lachenmeier, D. W. (2011) Determination of the biologically active flavour substances thujone and camphor in foods and medicines containing sage (Salvia officinalis L. Chem. Cent. J., 21, 544.

Yoshioka, T., Kawada, K., Shimada, T. and Mori, M. (1979) Lipid peroxidation in maternal and cord blood and prorective mechanism against activated oxygen toxicity in the blood. Am..J. Obstet. Gynecol., 135, 372.

Zhang, H. J., Zhao, W., Venkataraman, S., Robbins, M. E. C., Buettner, G. R., Kregel, K. C. and Oberley, L. W. (2002) Activation of matrix metalloproteinase- 2 by overexpression of manganese superoxide dismutase in human breast cancer mcf-7 cells involves reactive oxygen species. $J$. Biolog. Chem, 277, 2919.

(Received: 23/04/2013;

accepted: 11/06/2013)

Egypt. J. Rad. Sci. Applic., Vol. 26, No. 1-2 (2013) 


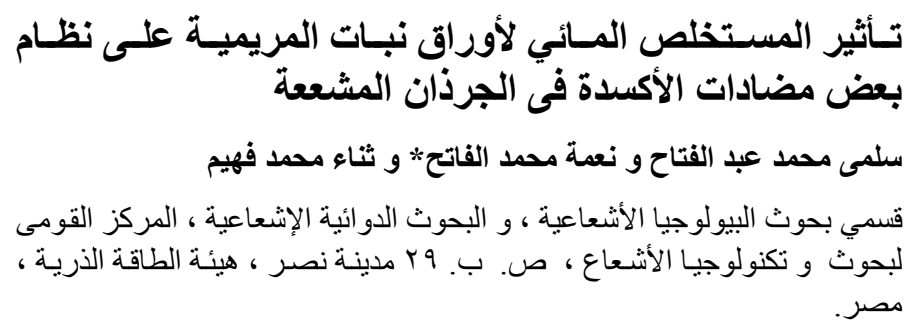

أوراق المريمية هو نبات عطري غني بالمركبات الفينوليه. ان الدور

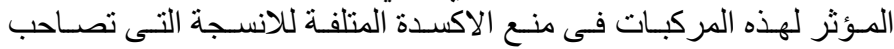

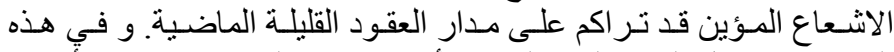

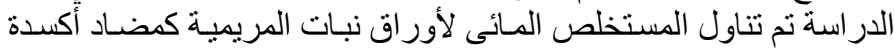

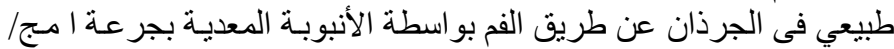

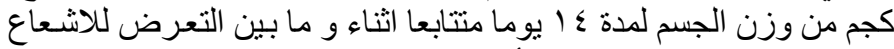

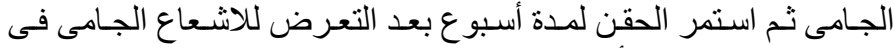

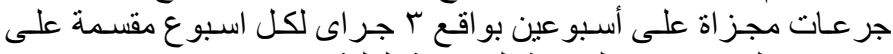

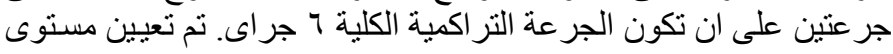

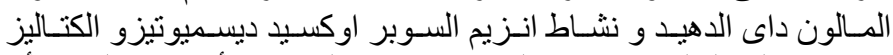

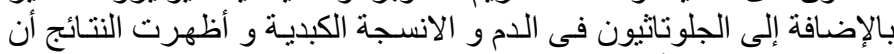

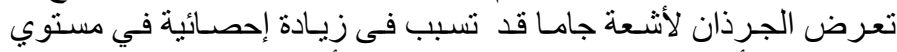

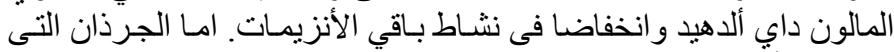

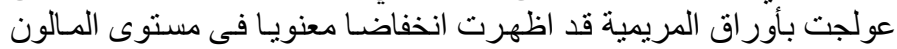
داي ألدهيد و تحسن معنوي فى كل الأنس النزيمات.

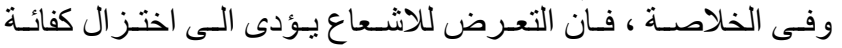

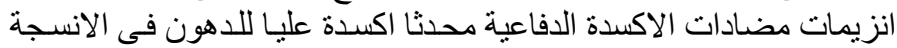

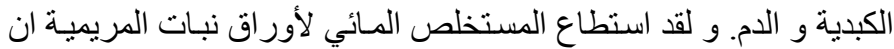

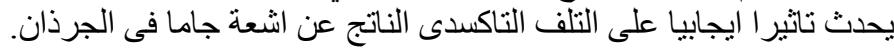

Egypt. J. Rad. Sci. Applic., Vol. 26, No. 1-2 (2013) 